\title{
The lunar tide in sporadic $\mathbf{E}$
}

\author{
R. J. Stening \\ School of Physics, University of New South Wales, Sydney 2052, Australia
}

Received: 25 January 1999 / Revised: 26 April 1999 / Accepted: 27 April 1999

\begin{abstract}
It seems that the wind shear theory is accepted for the explanation of sporadic E at mid and low latitudes. Some examples from Arecibo are displayed to show this. The effect of lunar tides should then modify the wind-shear theory in a manner that yields the observed features of the lunar tide in the critical frequency $f$ oEs and the height $\mathrm{h}^{\prime}$ Es of the sporadic E. This is shown to imply that the phase of the lunar tide in $h^{\prime}$ Es should be the same as the phase of the lunar tide in the eastward wind and that the phase of the lunar tide in $f$ oEs is three hours later. Hourly values of $f_{\mathrm{oEs}}, f$ bEs (the blanketing critical frequency) and $h^{\prime}$ Es from several observatories are analysed for the lunar semidiurnal tide. It is found that the phase of the tide in $f$ oEs is often about 3 hours later than for $h^{\prime} E s$ in agreement with the theory. Seasonal variations in the tide are also examined with the statistically most significant results (largest amplitudes) usually occurring in summer. After reviewing the many difficulties associated with determining the lunar tide in Es, both experimentally and theoretically, the analysed phase results are compared with what might be expected from Hagan's global scale wave model. Agreement is only fair (a success rate of $69 \%$ among the cases examined) but probably as good as might be expected.
\end{abstract}

Key words. Ionosphere (ionosphere - atmosphere interactions, ionospheric irregularities) · Meteorology and atmosphere dynamics (waves and tides)

\section{Introduction}

The lunar tides in the height of sporadic E, h'Es, and of its critical frequency, $f_{\mathrm{oEs}}$, were investigated many years ago. This early work is summarised by Matsushita (1967).

It is only recently that our knowledge of the lunar atmospheric tide and also of the sporadic E layer have reached the stage that it is possible to test various theories to explain the observations. Vial and Forbes (1994) produced a simulation of the lunar atmospheric tide which yielded fair agreement with observed lunar tides in winds at heights of 80 to $100 \mathrm{~km}$ (Stening and Vincent et al., 1989, Stening et al., 1994) but this model did not extend much above $100 \mathrm{~km}$. There does not appear to be any satisfactory direct measurement of lunar tides in neutral winds at heights of 100 to $140 \mathrm{~km}$ where sporadic $\mathrm{E}$ is found, but recent simulations do extend into that height region. The GSWM model of Hagan (1996) was used to experiment with lunar atmospheric tides (Stening et al., 1997) and those results will be used in this study.

Many of the observations and theories of sporadic E were summarised by Whitehead (1989). The most accepted theory still appears to be the wind-shear theory in which a reversal of the east-west neutral wind combines with the Earth's main magnetic field to produce upward and downward motions of heavy ions, so compressing them into a layer coincident with the height of wind reversal. More recent work by Kirkwood and von Zahn (1993) indicates that the electric field may play a part in situations where it is very large and the magnetic field is nearly vertical, such as in auroral regions, but that the wind-shear remains the dominant process. Mathews (1998) confirms this. He finds that, at Arecibo, these layers of enhanced ionisation are almost always present and prefers to call them tidal ion layers (TILs). He further notes that they are formed mainly by zonal winds below about $125 \mathrm{~km}$ and by meridional winds above that height.

The wind-shear theory of formation contradicts the conclusion of Tarpley and Matsushita (1972) who decided that the electrostatic fields were mainly responsible for the lunar tide in Es. They found an equation for the height at which the vertical ion velocity was zero. This height was given by

$z_{0}=\frac{\lambda}{2 \pi} \sin ^{-1}\left[\frac{1}{\beta u_{0}}\left(-\beta \frac{E_{x}}{B \sin I}+\gamma \frac{E_{y}}{B}\right)\right]$

where $\lambda$ is the vertical wavelength and $u_{0}$ the amplitude of the background tidal wind, $\beta$ and $\gamma$ are functions of 
the electron and ion collision and gyrofrequencies and, in the lower $\mathrm{E}$ region, $\beta \gg \gamma, E_{x}$ is the southward electrostatic field and $E_{y}$ the eastward electrostatic field produced by the lunar ionospheric dynamo, $B$ is the strength of the Earth's main magnetic field and $I$ is the magnetic inclination angle.

As the first term dominates in this equation, the lunar tide in $z_{0}$ comes to have the same phase as the lunar tide in $E_{x}$, namely a maximum at about 7 lunar h. This phase was measured by Tarpley and Balsley (1972) at the magnetic equator during daytime and has been confirmed in simulations of the lunar tide using the TIEGCM model (Stening et al., 1999). The latter model also gives a good simulation of the lunar tide in the $\mathrm{F}$ region of the ionosphere near the equator and so the value of $7 \mathrm{~h}$ is well supported. In this model the eastward wind phase is about $3 \mathrm{~h}$, measured at the bottom of the $\mathrm{E}$ region, around $100 \mathrm{~km}$ altitude. This value varies with latitude, with season and with height, as will be shown later. Since the majority of direct observations confirm that neutral wind shear is responsible for sporadic E, we prefer to examine the possibility that the lunar effects act in the same way. Equatorial sporadic E, which occurs within the equatorial electrojet and arises from an instability process, is not part of the present discussion.

Here I shall first look at a few new observations of sporadic $\mathrm{E}$ which will confirm the wind-shear theory, then postulate and discuss some theories which might explain the observed lunar phases of $h^{\prime}$ Es and $f$ oEs and then examine a range of new determinations of these phases for comparison with the theory.

\section{Observations of sporadic E}

Data from the Arecibo $\left(18.3^{\circ} \mathrm{N}, 66.75^{\circ} \mathrm{W}\right)$ incoherent scatter radar were used in this study. The data were accessed through the NCAR CEDAR data base. Among the parameters which can be determined by the radar are the ion density and the neutral winds. A typical plot of the height variation of these is shown in Fig. 1. It can be seen that the height of the sporadic E layer and the time of reversal of the wind from east to west can be read off from this plot. A series of such measurements were made on the same day and the two heights are seen to descend together as shown in Fig. 2. The mode of operation of the radar gives rise to the measurements of the different parameters occurring at different times. The different parameters are measured in a certain sequence. Another example is shown in Fig. 3. The agreement between the two heights is regarded as close enough to support the wind-shear theory. The occasional discrepancy may arise from extra structure in the wind profile in between measurements. For example in Fig. 3 there is a minimum in the wind at $1839 \mathrm{~h}$ near a height of $107 \mathrm{~km}$ but not a reversal.

It can be seen that the sporadic E occurs at the height where the wind changes from eastward at a lower height (giving an upward force on the ions) to westward at the greater height (giving a downward force).
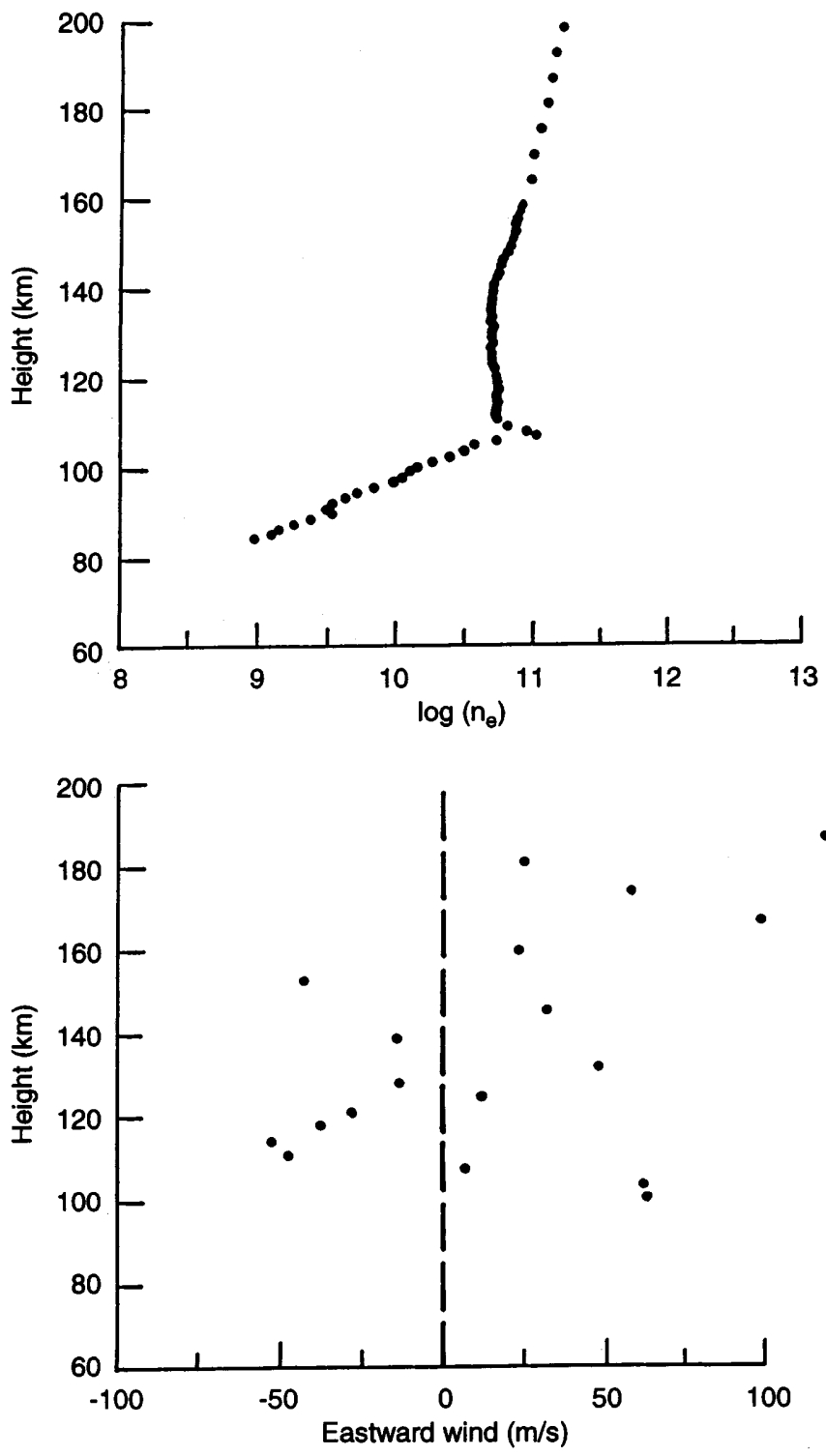

Fig. 1. Arecibo incoherent scatter radar data on April 19, 1977 at 2130 UT. The top panel shows the electron density as a function of height in a logarithmic plot. A sporadic E layer may be seen near $108 \mathrm{~km}$. The bottom panel shows eastward neutral winds and a reversal from eastward to westward occurs near $109 \mathrm{~km}$

\section{Theory of the lunar tide in sporadic $\mathbf{E}$}

In the summary of Matsushita (1967) it is found that, at many observatories, the lunar time of maximum $\tau_{\max }$ of foEs is around $7 \mathrm{~h}$ while $\tau_{\max }$ for h'Es is consistently earlier at about $6 \mathrm{~h}$. We will examine further determinations in the next section.

But what determines these times? Looking at Fig. 4, suppose the solid curve represents the variation with height of the neutral wind. Often this has a quasisinusoidal form with a vertical wavelength of about $20 \mathrm{~km}$. Now suppose a lunar tide in the winds is superposed over this. The lunar semidiurnal tide is expected to have a longer vertical wavelength (60 to $70 \mathrm{~km}$ ), so, when the lunar tide is maximum eastwards, 


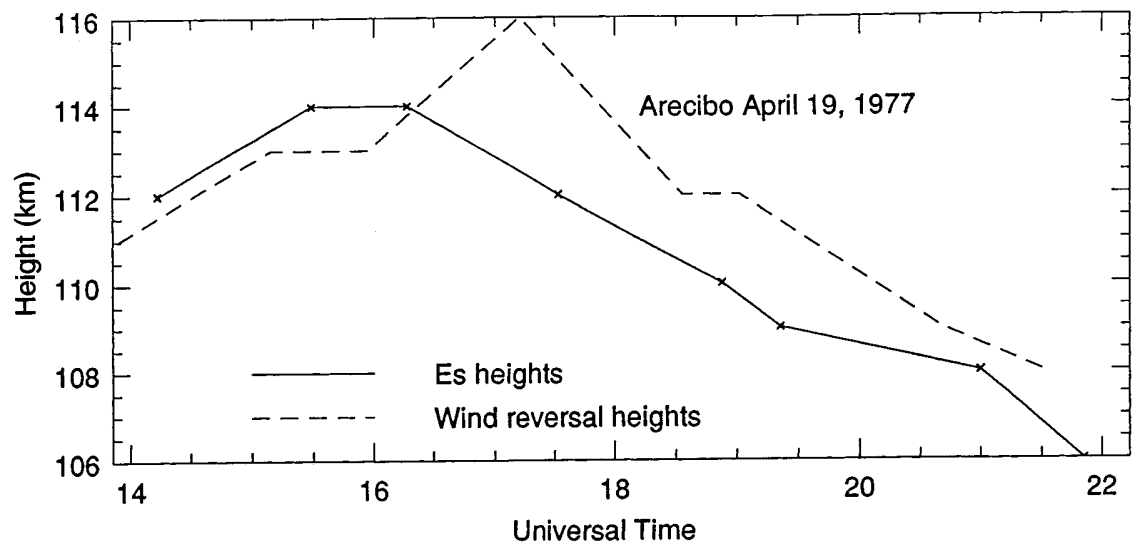

Fig. 2. Es heights and wind reversal heights variation with Universal Time determined at Arecibo as in Fig. 1 for April 19, 1977 it will displace the whole profile eastwards as shown. This will have the effect of moving the height of reversal (point A in the figure) upwards. It follows that when the lunar tide in the eastward wind is maximum, then the lunar tide in $h^{\prime}$ Es will also be maximum, so both these parameters should have the same $\tau_{\max }$. This will be tested in the next section.

But what determines when the lunar tide in foEs will be maximum? In order to answer this question we have to consider what factors determine the strength of the sporadic E. These will include the density of the background ionisation, the number of heavy ions present (due to meteor showers etc.) and the strength of the wind shear (amplitude of the rate of change of wind velocity with height).

The lunar tide in the normal (not sporadic) E region is small and, in our experience, rather irregular. Matsushita (1967) remarks that some analyses are contaminated with Es. If this were the source of the lunar tide in foEs then one would expect that the lunar tide in $f_{\mathrm{oE}}$ would have a similar phase. Tests that we have made indicate that this is rarely the case. We have no information on lunar effects on meteor showers, but even if there were a lunar monthly influence on these, it seems unlikely that there would be a lunar semidiurnal periodicity such as we are examining here.

There remains the effect of the eastward winds. It seems that if the wind-shear effect is to be maximised, then the lunar tidal effect must add to the effect of the other winds present. This means that the lunar tidal wind should reverse from eastward to westward at the same height as the other winds, namely at the height where the sporadic E layer occurs. Remembering that $\tau_{\max }$ gets earlier with increasing height, this means that we would expect that $\tau_{\max }$ would be $3 \mathrm{~h}$ later for $f_{\mathrm{oEs}}$ than for $h^{\prime}$ Es.

\section{Analysis of ionosonde data}

Most of the data used here were obtained from the CDROM provided by the National Geophysical Data Center in Boulder, Colorado. The analysis method used is that of Winch and Cunningham (1979). This is a modification of the Chapman and Miller (1940) method but it allows determination of seasonal and local time variations in the lunar semidiurnal tide. This method has the disadvantage that a complete set of $24 \mathrm{~h}$ of data is required for each day used in the analysis. In order that not too many days are discarded due to this requirement, an interpolation process is carried out: if only one or two data points are missing in succession they are filled by linear interpolation. In addition some stations have a rather low occurrence of sporadic $\mathrm{E}$ at night. For these the nighttime is filled with data equal to the nearest morning or evening values. In analysing for lunar tides one has to be very careful concerning statistical reliability of the results. Using this method we often

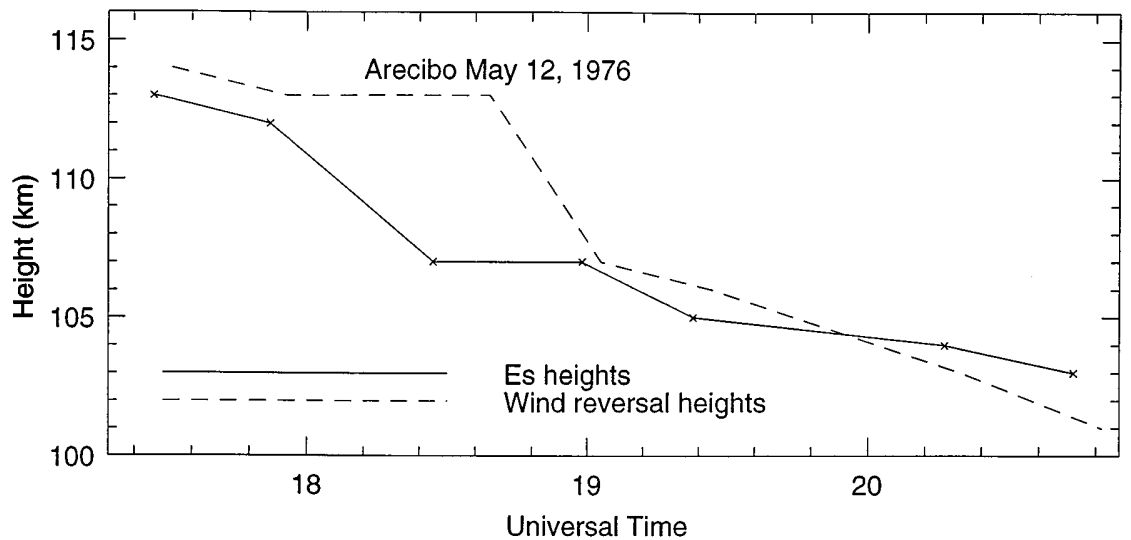

Fig. 3. As for Fig. 2 but for May 12, 1976 


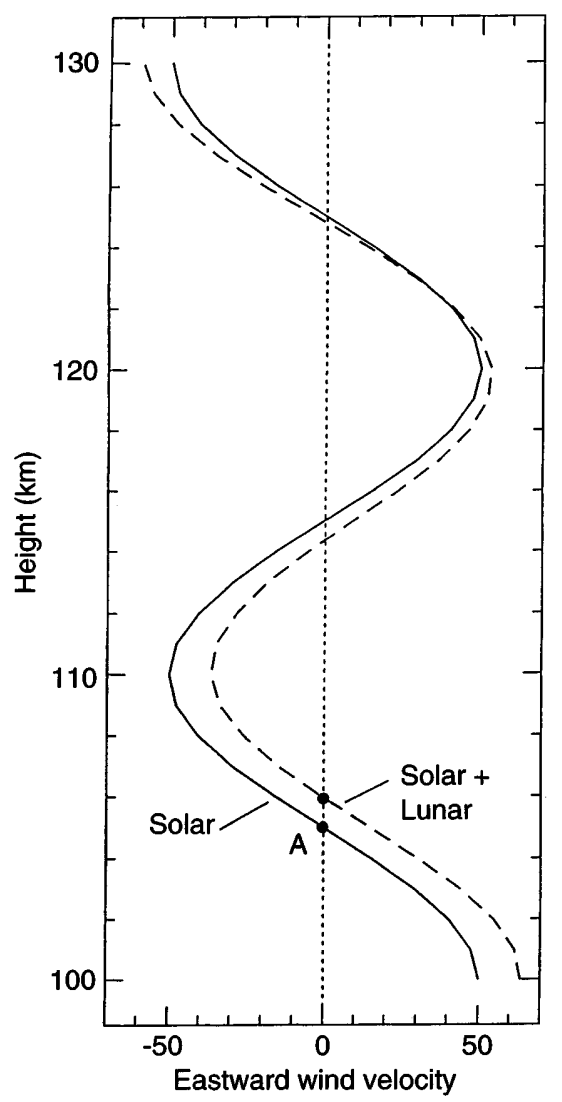

Fig. 4. Theory of lunar tide in Es. The solid line is a tidal wind with $\lambda_{z}=20 \mathrm{~km}$. The dashed line shows the effect of addition of another tide with $\lambda_{z}=60 \mathrm{~km}$. The point $A$ indicates the height of formation of sporadic E

discard all results which are below the $95 \%$ confidence limit. In doing this we have to be aware that $5 \%$ of our results may still be unreliable so that isolated significant results are generally not accepted. Another check is to compare results from different years: consistent values will have greater reliability.

In Fig. 5 we display a whole series of determinations of the phase of the lunar tide in sporadic $\mathrm{E}$ at Townsville (146.8E, 19.6S). The filled symbols refer to $h^{\prime}$ Es while the open symbols refer to $f$ oEs or to $f$ bEs, the critical frequency of blanketing sporadic E. Each determination uses 2 y of data analysed by the Winch-Cunningham method. The results are selected from the local times between 9 and $15 \mathrm{~h}$, so nighttime values, which are often different, are excluded. The errors in the displayed points are all less than $\pm 1 \mathrm{~h}$. Here we see some year-toyear variability but also some consistency. For example the phases for five different time periods were within one hour, around $3 \mathrm{~h}$, for h'Es in December. In places where there are two of the same symbols for the same month, these indicate the separate results for $f_{\mathrm{oEs}}$ and $f \mathrm{bEs}$. These are nearly always very close together. There are no $f$ oEs results from July to September because there were no statistically significant amplitudes recorded in those months. The number of days accepted after removal of days with many missing data points was in fact rather higher for $f_{\mathrm{oEs}}$ and than for h'Es, yet fewer

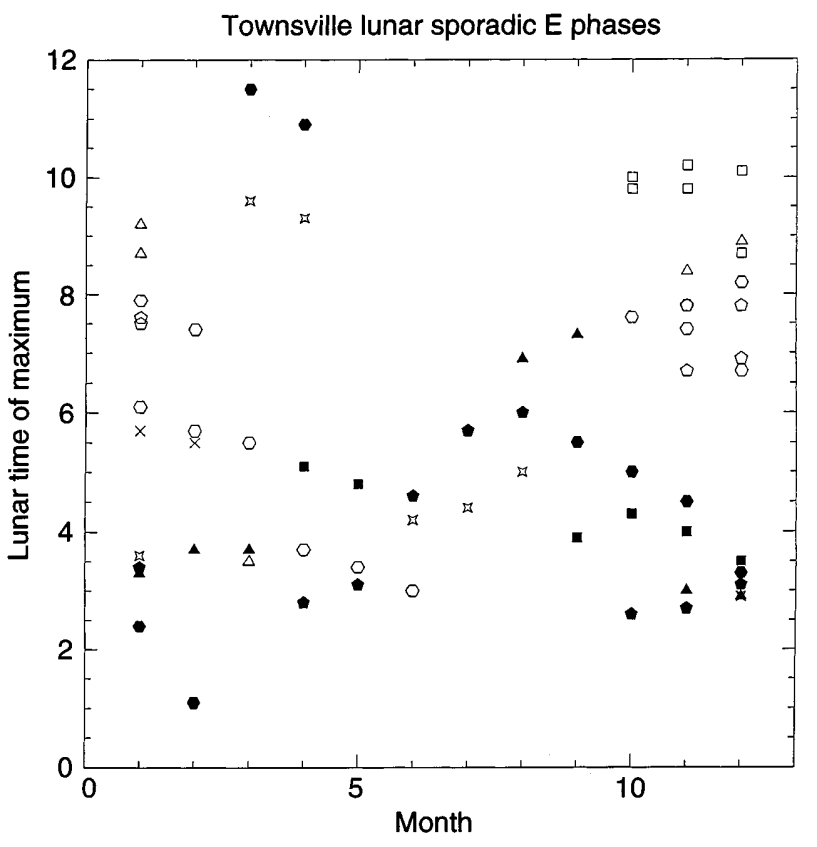

Fig. 5. A series of determinations of the phase of the lunar tide in Es at Townsville as a function of month of the year. Solid symbols represent $\mathrm{h}^{\prime} \mathrm{Es}$ and open symbols represent $f_{\mathrm{OEs}}$ or $f \mathrm{bEs}$. Different symbols represent different two-year data sets. See text for more details

foEs results were significant. The occurrence and strength of Es is largest during the summer months, here November to January. In the months of April and May there are two groups of phases $6 \mathrm{~h}$ apart (in antiphase).

We have seen from Fig. 5 that there is often a yearto-year variation in the phase of the lunar tide and this is confirmed in some analyses of the winds themselves (Stening et al., 1994). With longer time series these variations are averaged out and the traditional idea of using the largest possible time series may not be appropriate. Nevertheless we will show analyses from three observatories using such longer data series.

In Figs. 6, 7 and 8 some points do not meet the 95\% confidence limit. The reader can identify such cases when the standard deviation of the amplitude (shown by the error bars) is greater than half of the amplitude value.

In Fig. 6 we present data from Maui (203.5E, 20.8N), a similar latitude to Townsville but in the Northern Hemisphere. Here 12 y of data are analysed together. Except in January the phase of $f$ oEs is later than that of $h^{\prime} E s$. The phase switch in $h^{\prime} E s$ in June and July seems to be a significant feature. The variation of the amplitude of the lunar tides with season are also shown with the tide in h'Es having an average amplitude around $2 \mathrm{~km}$, rising to $3 \mathrm{~km}$ in winter. Even with $12 \mathrm{y}$ data the amplitude of the lunar tide in foEs is below the $95 \%$ significance level in August and September.

Similar plots are provided in Fig. 7 for Darwin $\left(12.4^{\circ} \mathrm{S} 131^{\circ} \mathrm{E}\right)$ using 8 y data from 1983 to 1990 and in Fig. 8 for Vanimo $\left(2.7^{\circ} \mathrm{S}, 141.3^{\circ} \mathrm{E}\right)$ using $14 \mathrm{y}$ data from 1976 to 1989 . At Darwin the phase of the $f$ oEs tide is $3 \pm 1$ hours later than that of the h'Es tide for four of the 

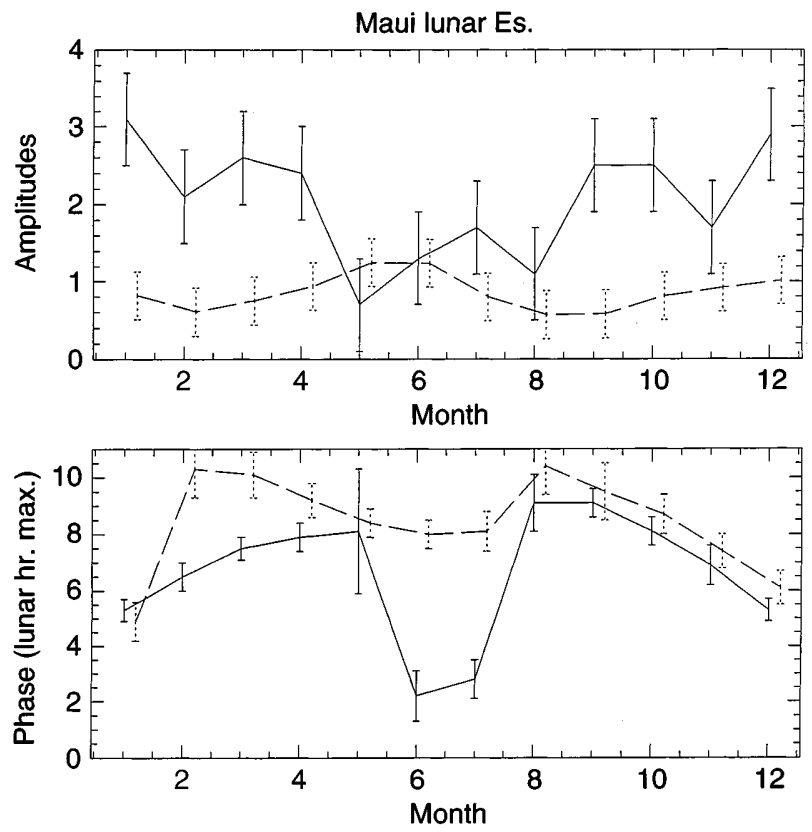

Fig. 6. Variation of amplitude and phase with season of the lunar tide in Es at Maui. Data are from 1976 to 1987. The solid line is for $\mathrm{h}^{\prime} \mathrm{Es}$ and the dashed line for $f_{\mathrm{oEs}}$. The $\mathrm{h}^{\prime} \mathrm{Es}$ amplitudes are in $\mathrm{km}$ and the $f_{\mathrm{oEs}}$ amplitudes in $0.1 \mathrm{MHz}$. The $f_{\mathrm{oEs}}$ points are slightly offset along the time axis so the error bars ( \pm one standard deviation) do not overlap

months. A variety of relationships exist in the other months. The phase jump in h'Es between February and March is similar to that seen at the end of summer at Maui.

Vanimo is very close to the geographic equator. A $3 \pm 1.5 \mathrm{~h}$ phase difference between $f$ oEs and h'Es can
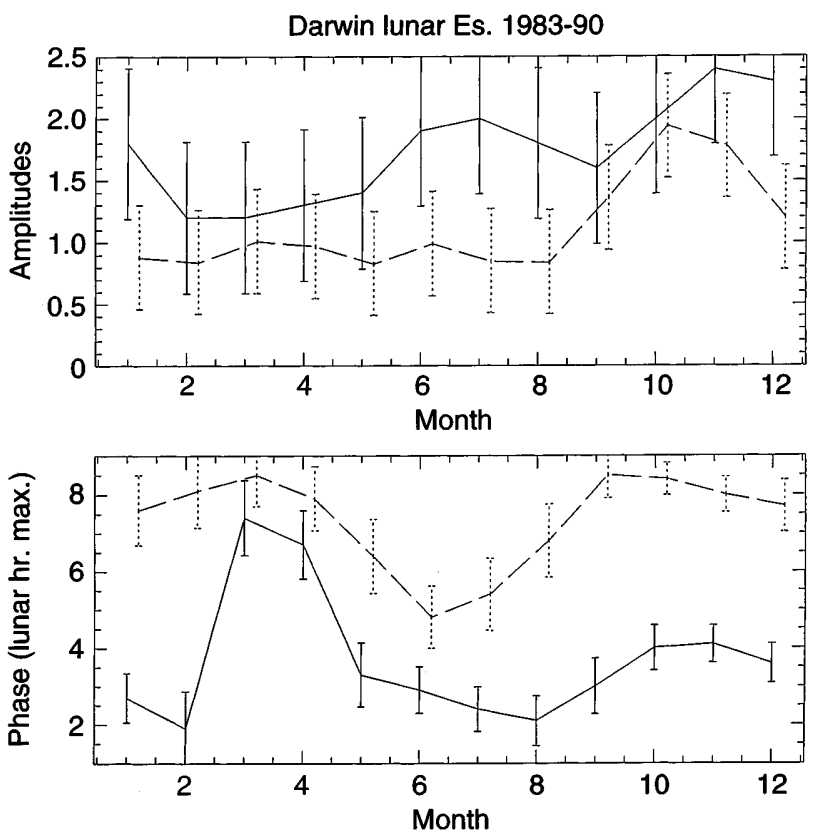

Fig. 7. Variation of amplitude and phase with season of the lunar tide in Es at Darwin. Data are from 1983 to 1990. Other details are the same as Fig. 6
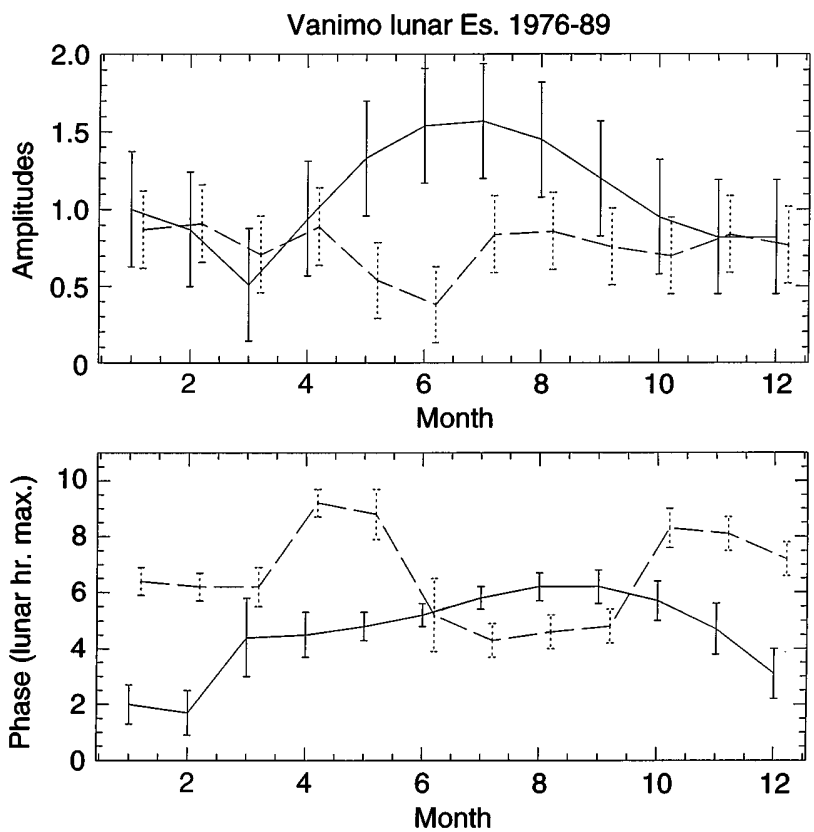

Fig. 8. Variation of amplitude and phase with season of the lunar tide in Es at Vanimo. Data are from 1976 to 1989. Other details are the same as Fig. 6

be seen from October to February. June to September appear anomalous with $h^{\prime}$ Es having the later phase. However this may partly be due to averaging as the following examples show:

1. For July 1982-83 data at 9 LT the h'Es phase is $8.9 \mathrm{~h}$ and the $f_{\mathrm{oEs}}$ phase is $13.6 \mathrm{~h}$.

2. For June $1984-85$ data at 13 LT the $h^{\prime}$ Es phase is $5.3 \mathrm{~h}$ and the $f$ oEs phase is $8.2 \mathrm{~h}$.

3. For June 1986-87 data at 13 LT the h'Es phase is $2.3 \mathrm{~h}$ and the $f$ oEs phase is $5.5 \mathrm{~h}$.

All these quoted examples have close to the suggested $3 \mathrm{~h}$ phase difference but quite different individual values. Differences from the $3 \mathrm{~h}$ phase difference still occur relatively frequently but it remains as the most predominant relationship.

When the variation of phase and amplitude of the tides with local time are examined, it is found that the amplitudes are often only statistically significant for a few hours a day. Sometimes the $f_{\text {oEs }}$ tide may be significant at different hours to the $h^{\prime}$ Es tide. Analyses by earlier workers, which did not display a local time dependence, would also have been influenced by this dependence. It creates a further problem in comparing the two parameters as the height of the Es layer may be different at the different local times and so the characteristics of the neutral atmosphere lunar tide may also be different.

\section{Comparison with theory}

In order to test the theories advanced earlier we need some estimate of the lunar tide in the neutral eastward winds in the E region of the ionosphere. The GSWM 
model of Hagan et al. (1992, 1995$)$ has been modified to calculate lunar tides (Stening et al., 1997). In this model the lunar forcing is taken from Vial and Forbes (1994) and includes gravitational forcing and also that due to the movement of the ocean and earth at the lower boundary. Vial and Forbes (1994) have demonstrated reasonable agreement of the model with observed lunar tides in the winds around heights of 80 to $100 \mathrm{~km}$.

In order to test our theory we need to know at what height the lunar phase of the neutral wind needs to be measured. This presents a problem as the height of Es layers is very variable from day to day and the phase of the wind varies with height. Figure 9 shows the variation with height of the lunar phase in the wind as calculated from the GSWM model. The best we can do to check the theory is to find the average height of the sporadic $\mathrm{E}$ and use this to determine a phase for the wind.
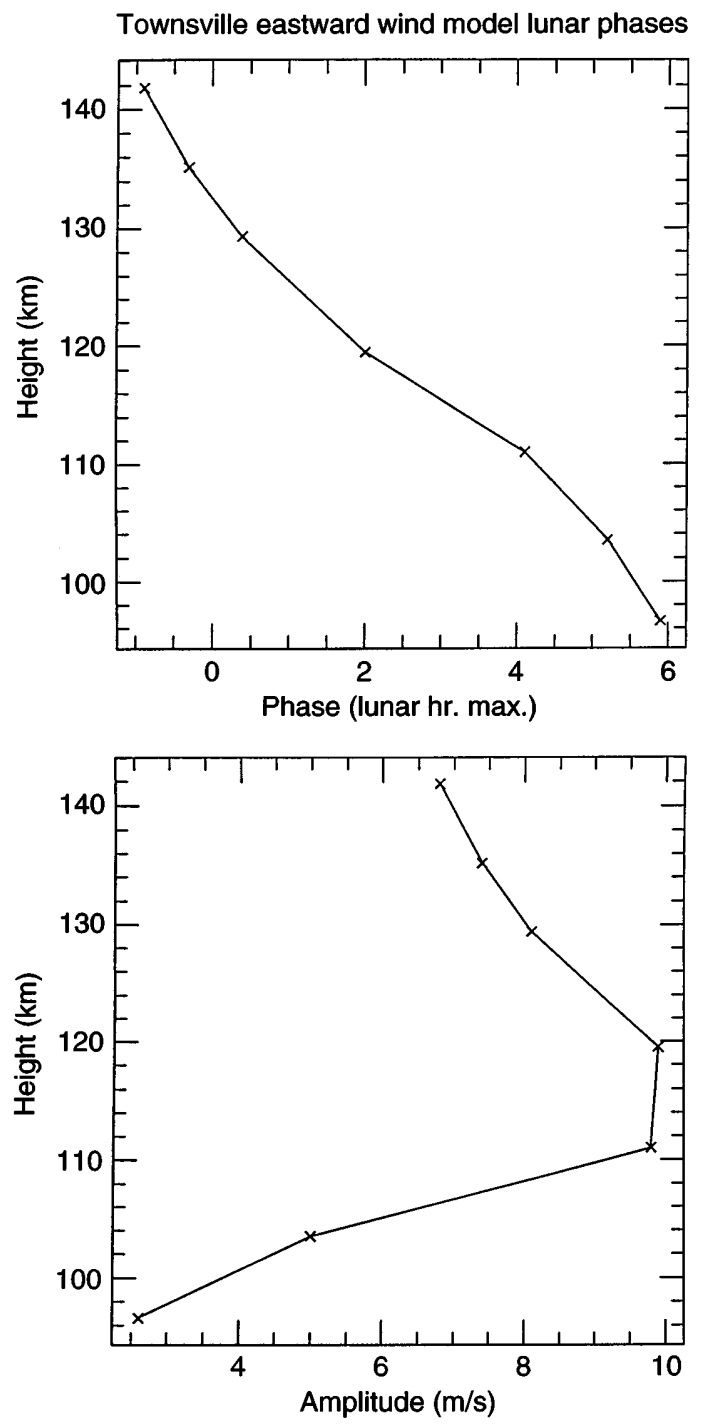

Fig. 9. Variation of phase and amplitude of the lunar tide in the eastward wind as determined by the GSWM at the location of Townsville $\left(22^{\circ} \mathrm{S}\right)$ in December
Table 1 gives some results of this procedure for daytime. Each entry corresponds to a significant $(95 \%$ confidence level) lunar tide in Es with the local time indicating when the lunar amplitude was largest. The lunar times of maximum of $\mathrm{h}^{\prime}$ Es and, where available, of $f_{\text {oEs }}$ are noted. In order to check agreement with the GSWM model of the lunar tide, we need a height at which to examine the GSWM theoretical result. The appropriate height is that where the sporadic E layer has been formed by the background tide. We have chosen an average value from the corresponding Es data for the particular local time, month and years. This is probably the least accurate aspect of the comparison because this height varies very considerably from day to day and a lunar tide necessarily has to be estimated from many days' data. The lunar time of maximum of the eastward wind at the h'Es height is determined from the GSWM model. If this time agrees with the experimentally determined lunar time to within $2 \mathrm{~h}$, then a tick is given in the last column. From this particular data collection we have a score of 11 agreements out of 16 or $69 \%$. This exercise probably illustrates the difficulty of making such a comparison more than proving the relationship that has been proposed. We should also note that, above $125 \mathrm{~km}$, the northward wind should probably be used instead of the eastward wind (Mathews, 1998). The northward wind should have its lunar time of maximum $3 \mathrm{~h}$ later. Taking this into account does not significantly change the statistics.

There are some cases where two separate amplitude peaks occur in the analysis at different times of the day with associated different phases. For example from August to October at Vanimo there is one peak in $h^{\prime} E s$ around $3 \mathrm{LT}$ with phase about $2 \mathrm{~h}$ (GSWM $1.8 \mathrm{~h}$ ) and another around $12 \mathrm{LT}$ with phase $6 \mathrm{~h}$ (GSWM $2.9 \mathrm{~h}$ ). And from December to January there are two peaks in $f$ oEs at Vanimo. One around $8 \mathrm{LT}$ has a phase of $4 \mathrm{~h}$ (GSWM $1.1+3=4.1 \mathrm{~h}$ ) and one around $15 \mathrm{LT}$ has a phase of $6 \mathrm{~h}(\mathrm{GSWM} 1.8+3=4.8 \mathrm{~h})$. In these results the GSWM values refer to the lunar time of maximum for the eastward wind at the appropriate h'Es height and at the latitude of Vanimo. There happens to be a pretty fair agreement for these. Notice that the maximum amplitude features in the analysis are different for $\mathrm{h}^{\prime} \mathrm{Es}$ and for $f_{\mathrm{oEs}}$.

Tarpley and Matsushita (1971) have examined the lunar tide in the sporadic E blanketing frequency $f$ bEs. They concluded that the lunar tide in $f$ bEs had about half the amplitude of the tide in foEs. This comparison was studied and the results are displayed in Table 2. Most results in Table 2 refer to maximum amplitudes at a particular local time and, while most of these show the amplitude of $f$ oEs to be greater, the difference does not always exceed the error and so is not statistically significant. Two entries show vector average (Vec Av)

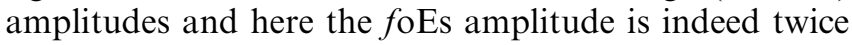
as large. This vector averaging over all local times is implicit in the results of Tarpley and Matsushita (1971).

Another factor to be considered is the influence of isolated large values in the data set. Just a few of these 
Table 1. Comparison of lunar Es phases with those determined from the GSWM model

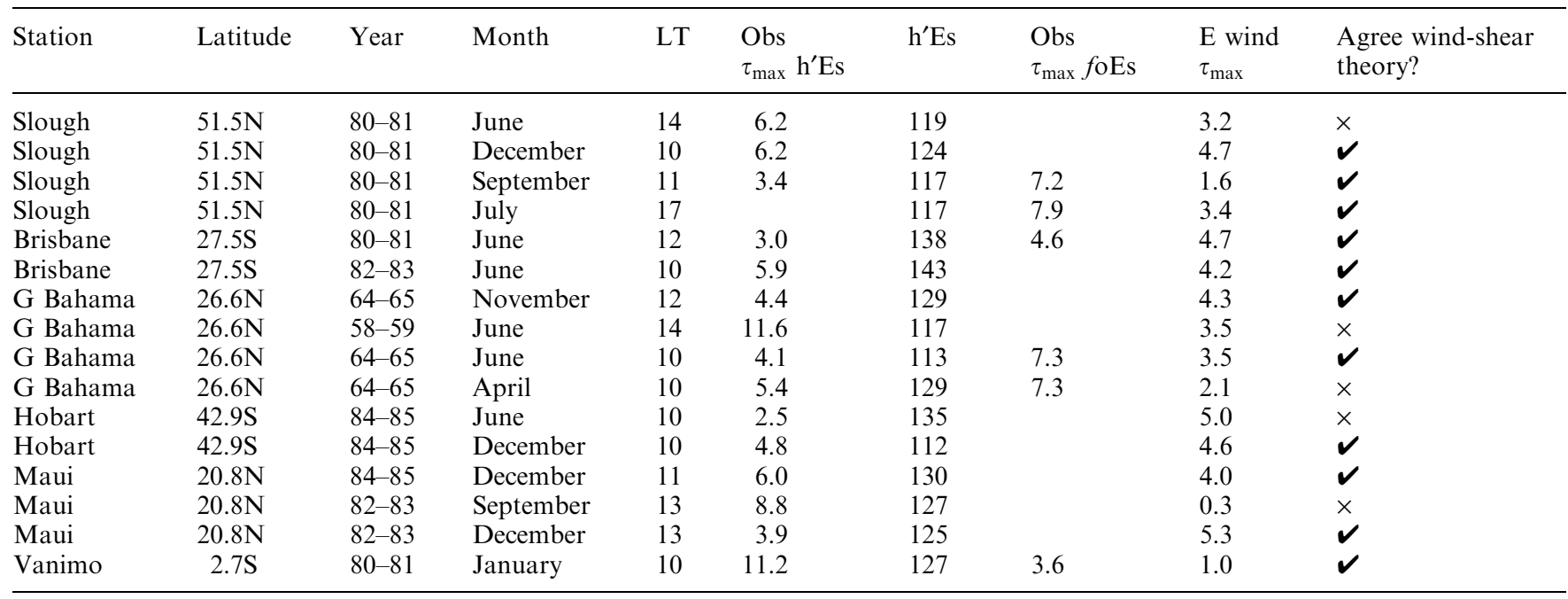

Table 2. $f_{\mathrm{oEs}}$ and $f$ bEs comparison

\begin{tabular}{|c|c|c|c|c|c|c|c|}
\hline Station & Years & Month & LT & foEs amplitudes & Phase & fbEs amplitude & Phase \\
\hline Maui & $82-87$ & April & 19 & $1.2 \pm 0.4$ & 11.4 & $0.9 \pm 0.3$ & 10.8 \\
\hline Maui & $82-87$ & May & Vec Av & $0.7 \pm 0.2$ & 10.3 & $0.3 \pm 0.1$ & 9.8 \\
\hline Maui & $82-87$ & January & Vec Av & $0.7 \pm 0.2$ & 6.2 & $0.3 \pm 0.1$ & 5.7 \\
\hline Townsville & $86-87$ & April & 18 & $2.3 \pm 0.8$ & 3.3 & $1.4 \pm 0.6$ & 3.4 \\
\hline G Bahama & $64-65$ & April & 17 & $2.2 \pm 0.8$ & 10.5 & $1.2 \pm 0.6$ & 9.6 \\
\hline
\end{tabular}

Amplitudes and their standard errors are in $\mathrm{MHz} \times 10$. Phases are lunar hour of maximum

${ }^{\mathrm{a}}$ Indicates very large values removed from data

can dramatically change lunar tidal amplitudes. Tarpley and Matsushita (1972) excluded all values greater than $6 \mathrm{MHz}$ from their data. We have run a few tests by removing days with values greater than $10 \mathrm{MHz}$. Two examples using this procedure are included in the table and these show even less difference between $f_{\mathrm{O}} \mathrm{Es}$ and $f$ bEs. These different ways of treating the data will clearly yield different amplitudes but the phases generally remain relatively unchanged.

\section{Conclusions}

1. There are considerable year-to-year changes in the measured phases of the lunar tide in sporadic E.

2. The phase of the lunar tide in $f_{\mathrm{oEs}}$ is usually later than the phase of $h^{\prime}$ Es with a phase difference of $3 h$ occurring most frequently.

3. This phase difference can be explained in terms of the wind-shear theory and the phase of the lunar tide in $h^{\prime}$ Es should be the same as that of the lunar tide in the eastward wind.

4. While the lunar tide in $f_{\mathrm{o}}$ Es is often larger than that in $f$ bEs, it is not as much as twice as large and the two amplitudes are often not significantly different.
5. Comparisons with models of the atmospheric lunar tide are somewhat inconclusive. The variability of the sporadic E phenomenon and of the lunar tide itself seems to mitigate against further progress in such a study.

Acknowledgements. Most of the hourly value data analysed were taken from the CDROM provided by the National Geophysical Data Center, Boulder, Colorado. The Arecibo data were accessed from the CEDAR data base. The Arecibo Observatory is operated by Cornell University in a cooperative agreement with the National Science Foundation. The lunar modification to the GSWM was developed while the author was a guest at the High Altitude Observatory, NCAR, working with J.M. Forbes, M.E. Hagan and A.D. Richmond.

Topical Editor F. Vial thanks D.M. Schlapp and another referee for their help in evaluating this paper.

\section{References}

Chapman, S., and J. C. P. Miller, The statistical determination of the lunar daily variations in geomagnetic and meteorological elements, Mon Not. Geophys. Supp., 4, 649-669, 1940.

Hagan, M. E., F. Vial, and J. M. Forbes, Evidence of variability in upward propagating semidiurnal tides due to effects of QBO in the lower atmosphere, J. Atmos. Terr. Phys., 54, 1465-1474, 1992

Hagan, M. E., J. M. Forbes, and F. Vial, On modeling migrating solar tides, Geophys. Res. Lett., 22, 893-896, 1995. 
Hagan, M. E., Comparative effects of migrating solar sources on tidal signatures in the middle and upper atmosphere, J. Geophys. Res., 101, 21 213-21 222, 1996.

Kirkwood, S., and U. von Zahn, Formation mechanisms for low latitude Es and their relationship with neutral Fe layers: results from the METAL campaign, J. Geophys. Res., 98, 21 549$21561,1993$.

Matsushita, S., Lunar tides in the ionosphere, Handbuch der Physik, vol XLIX/2, pp. 547-602, Springer, Berlin Heidelberg New York, 1967.

Mathews, J. D., Sporadic E: current views and recent progress, J. Atmos. solar-Terr. Phys., 60, 413-435, 1998.

Stening, R. J., and R. A. Vincent, A measurement of lunar tides in the mesosphere at Adelaide, South Australia, J. Geophys. Res., 94, 10 121-10 129, 1989.

Stening, R. J., A. H. Manson, C. E. Meek, and R. A. Vincent, Lunar tidal winds at Adelaide and Saskatoon at 80 to $100 \mathrm{~km}$ heights, 1985-1990, J. Geophys. Res., 99, $13273-$ $13280,1994$.
Stening, R. J., J. M. Forbes, M. E. Hagan, and A. D. Richmond, Experiments with a lunar atmospheric model, J. Geophys. Res., 102, 13 465-13 471, 1997.

Stening, R. J., A. D. Richmond, and R. G. Roble, Lunar tides in the thermosphere-ionosphere-electrodynamics general circulation model, J. Geophys. Res., 104, 1-14, 1999.

Tarpley, J. D., and B. B. Balsley, Lunar variations in the Peruvian electrojet, J. Geophys. Res., 77, 1951-1960, 1972.

Tarpley, J. D., and S. Matsushita, The lunar tide in fbEs, Radio Sci., 6, 191-196, 1971.

Tarpley, J. D., and S. Matsushita, Lunar influences on sporadic E, Radio Sci., 7, 411-416, 1972.

Vial, F., and J. M. Forbes, Monthly simulations of the lunar semidiurnal tide, J. Atmos. Terr. Phys., 56, 1591-1607, 1994.

Whitehead, J. D., Recent work on mid-latitude and equatorial sporadic-E, J. Atmos. Terr. Phys., 51, 401-424, 1989.

Winch, D. E., and R. A. Cunningham, Lunar magnetic tides at Watheroo: seasonal, elliptic, evectional, variational and nodal components, J. Geomagn. Geoelectr., 24, 381-414, 1972. 